\title{
Radiation- and Photo-Induced Degradation of Five Isomers of 1,2,3,4,5,6-Hexachlorocyclohexane
}

\author{
Masayuki Hamada, Eiko Kawano, Shunichi Kawamura \\ and Motoo SHIRO* \\ Radiation Center of Osaka Prefecture, Sakai, Osaka 593, Japan \\ * Shionogi Research Laboratory, Shionogi \& Co. Ltd., \\ Fukushima-ku, Osaka 553, Japan \\ Received August 11, 1980
}

\begin{abstract}
$\gamma$-Isomer of 1,2,3,4,5,6-hexachlorocyclohexane (BHC) showed greater decomposition on $\gamma$ or UV irradiation of five isomers of BHC in crystalline state or in 2-propanol solution. The $\alpha$ - and $\delta$-isomer of BHC and known 1a, 2a, 3e, 4e, 5e-pentachlorocyclohexane were separated from the irradiation product of crystalline $\gamma$-BHC. Four compounds were isolated from the irradiation product of $\gamma$-BHC in 2-propanol. Two compounds were tetrachlorocyclohexenes $\left(\mathrm{C}_{6} \mathrm{H}_{6} \mathrm{Cl}_{4}\right): \gamma$-isomer $\left(\mathrm{mp} 86 \sim 87^{\circ} \mathrm{C}\right)$ and s-isomer $\left(\mathrm{mp} 99 \sim 100^{\circ} \mathrm{C}\right)$. The other two were isomers of pentachlorocyclohexane $\left(\mathrm{C}_{6} \mathrm{H}_{7} \mathrm{Cl}_{5}\right)$. One of them $\left(\mathrm{mp} 78 \sim 8.5^{\circ} \mathrm{C}\right.$ ) was consistent with known meso-1e,2a,3a,4a,5e isomer. The molecular structure of the other $\left(\mathrm{mp} 75^{\circ} \mathrm{C}\right)$ established by X-ray crystal structure analysis was $1 \alpha, 2 \alpha, 3 \alpha, 4 \beta, 5 \alpha$ configuration or $1 \mathrm{e} 2 \mathrm{a} 3 \mathrm{e} 4 \mathrm{e} 5 \mathrm{e}$ conformation of $\mathrm{Cl}$ atoms. A reaction mechanism was proposed that included a radical chain reaction and chlorine atom migration.
\end{abstract}

Much attention has been focused on the environmental pollutions caused by polychlorinated hydrocarbons such as BHC $(1,2,3$, 4,5,6-hexachlorocyclohexane), DDT (1,1,1trichloro-2,2-bis( $p$-chlorophenyl)ethane) and PCB (polychlorinated biphenyl). In general, these compounds are resistant toward decomposition or conversion to biologically harmless substances under mild chemical or photochemical conditions, or in the presence of micro-organisms. Therefore, these compounds remain in the environment for a long period and are apt to show a variety of unfavorable effects.

Several papers have been presented on the decomposition reactions of these chlorinated compounds under $\mathrm{UV}$ and ionization radiation. Among these compounds, PCB was partially dechlorinated to lower chlorinated biphenyls by UV in certain organic solutions ${ }^{1,2)}$ and underwent dechlorination more easily by UV or ionizing radiation in the alkaline solution. $^{3 \sim 7)}$, DDT underwent dechlorination to DDD (1,1-dichloro-2,2-bis( $p$-chlorophenyl)ethane) with large $G$ value by the $\gamma$-ray irradiation of the 2-propanol solution. ${ }^{8 \sim 10}$ When each isomer of BHC was irradiated with $1 \mathrm{MeV}$ electrons in a crystalline state, both dehydrochlorination and isomerization were observed by gas-chromatography. ${ }^{11}$, Photoinduced dechlorination of $\beta$ - and $\gamma$ isomer of BHC in alkaline solution was also reported. ${ }^{12,13)}$

This paper deals with the radiation- and photo-induced reaction of five isomers of BHC in a crystalline state or in 2-propanol solution, and the identification of the main compounds isolated from the irradiated products of $\gamma$ isomer of $\mathrm{BHC}$ in 2-propanol.

When $\alpha-, \beta$ - and $\delta$-isomer of BHC were irradiated in a crystalline state at a dose of about $10^{8} \mathrm{R}$ by ${ }^{60} \mathrm{Co} \gamma$-ray, only slight decomposition was observed in each case. However, in the irradiation of the $\gamma$-isomer in the same state at a dose of $4.8 \times 10^{8} \mathrm{R}, \alpha$-isomer of $\mathrm{BHC}$ was obtained as the major product, and an isomer of pentachlorocyclohexane $\left(\mathrm{C}_{6} \mathrm{H}_{7} \mathrm{Cl}_{5}\right)$ and $\delta$-isomer of $\mathrm{BHC}$ were also produced. After preparative fractionation by a liquid chromatography and the following recrystalli- 
zation, the pentachlorocyclohexane was confirmed to be the known racemic isomer by $\mathrm{mp}^{14)}$ and $\mathrm{NMR}^{15)}$ whose configuration is $1 \alpha$, $2 \beta, 3 \beta, 4 \alpha, 5 \beta$ and the conformation of chlorine atoms is $1 \mathrm{a} 2 \mathrm{a} 3 \mathrm{e} 4 \mathrm{e} 5 \mathrm{e}$. Above findings are considerably different from the result obtained by Elias et al $^{11}{ }^{11}$ in which $\delta$-pentachlorocyclohexene $\left(\mathrm{C}_{6} \mathrm{H}_{5} \mathrm{Cl}_{5}\right)$ and several chlorinated benzenes were identified from the gas chromatograph of the products obtained by the irradiation of $\gamma$-BHC crystals with $1 \mathrm{MeV}$ electrons.

When the solution of each isomer of $\mathrm{BHC}$ in 2-propanol was irradiated by ${ }^{60} \mathrm{Co} \gamma-\mathrm{ray}^{16)}$, the $G$ values of the decomposition of $\alpha-, \beta$-, $\gamma$-, $\delta$ - and $\varepsilon$-isomer were $5.2,3.4,42.0,5.4$ and 7.4 , respectively, under $120 \mathrm{~min}$ irradiation at a dose rate of $5 \times 10^{5} \mathrm{R} / \mathrm{h}$. $\gamma$-Isomer undergoes much more decomposition than the other isomers by ionizing radiation, and the decomposition rates of $\gamma$-isomer at three different dose rates are shown in Fig. 1. When $\gamma$-isomer in 2-propanol was irradiated for $15 \mathrm{~min}$ by UV of $15 \mathrm{~W}$ low pressure mercury lamp, the gas-chromatogram of the decomposition products was similar to that of the product obtained by $120 \mathrm{~min}$ irradiation at $5 \times 10^{5} \mathrm{R} / \mathrm{h}$ by $\gamma$-ray.

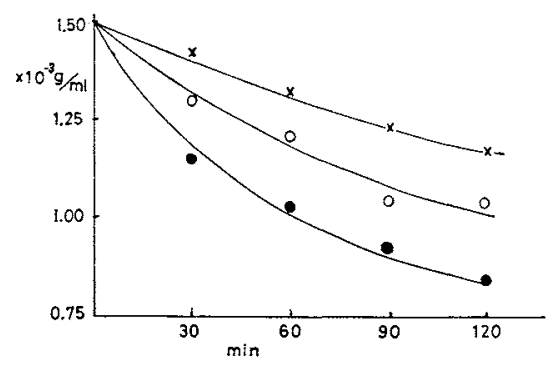

FIG. 1. Decrease of the Amount of $\gamma$-Isomer of BHC in 2-Propanol at Three Different Dose Rates.

$1.25 \times 10^{5} \mathrm{R} / \mathrm{h},(\times-\times) ; 2.5 \times 10^{5} \mathrm{R} / \mathrm{h},(\mathrm{O}-\mathrm{O}) ; 5 \times$ $10^{5} \mathrm{R} / \mathrm{h}(-)$.
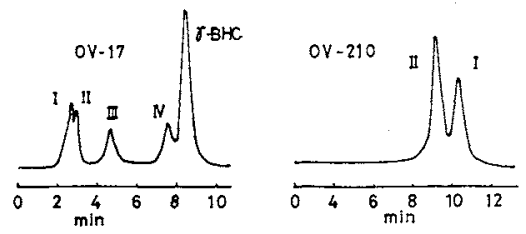

FIG. 2. Gas-chromatograms of the Irradiated Product of $\gamma$-Isomer of BHC on OV-17 and OV-210.
Typical gas-chromatograms (GLC) of the product obtained by the irradiation of $\gamma$-BHC under the above conditions are shown in Fig. 2 in which the presence of four main decomposition compounds was observed. Although the separation of compound I and II in the product was incomplete with $\mathrm{OV}-17$ column of GLC, OV-210 column operated at $120^{\circ} \mathrm{C}$ was effective for the separation of the two compounds. The separation of the products by high performance liquid chromatography (HPLC) is shown in Fig. 3, in which the

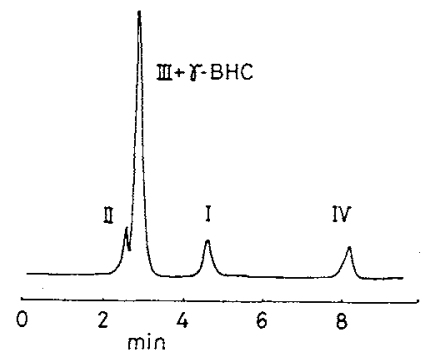

Frg. 3. High Performance Liquid Chromatogram of the Irradiated Product of $\gamma$-Isomer of $\mathrm{BHC}$ on $\mu$-Porasil 8 .

retention time of the compound III was almost same as that of $\gamma$-BHC. The fractionation of four main compounds was performed by a preparative liquid chromatograph packed with silicic acid moistened with nitromethane. The elution order of these compounds by the liquid chromatography was $\gamma$-BHC, compound III, II, I and IV. After repetition of the fractionation by the liquid chromatography, recrystallization, and the monitoring of the purity of each fraction by GLC and HPLC, four compounds were obtained in pure state from the irradiated products. The relative retention times to $\gamma-\mathrm{BHC}, \mathrm{mp}, \mathrm{M}^{+}$by $\mathrm{MS}$ and molecular formula of these compounds are presented in Table $\mathrm{I}$.

The compound I whose relative retention time on OV-17 column of GLC was 0.31 and that on OV-210 column was 0.27 showed mp $86 \sim 87^{\circ} \mathrm{C}$ and $\mathrm{M}^{+} 218$. From elementary analysis and MS spectrum, this compound was concluded to be an isomer of tetrachlorocyclohexene $\left(\mathrm{C}_{6} \mathrm{H}_{6} \mathrm{Cl}_{4}\right)$. From the agreement 
Table I. Relative Retention Times to $\gamma$-BHC, Mp, $\mathrm{M}^{+}$and Molecular Formula of Four Compounds Separated from the Irradiated Product

\begin{tabular}{rcccccc} 
& \multicolumn{2}{c}{$\begin{array}{c}\text { Relative retention } \\
\text { time }\end{array}$} & mp $\left({ }^{\circ} \mathrm{C}\right)$ & $\mathrm{M}^{+}$ & $\begin{array}{c}\text { Molecular } \\
\text { formula }\end{array}$ & Identification \\
\cline { 2 - 4 } & $\mathrm{OV}-17$ & $\mathrm{OV}-210$ & & & & \\
\hline I & 0.31 & 0.27 & $86 \sim 87$ & 218 & $\mathrm{C}_{6} \mathrm{H}_{6} \mathrm{Cl}_{4}$ & $r$-BTC \\
II & 0.33 & 0.24 & $99 \sim 100$ & 218 & $\mathrm{C}_{6} \mathrm{H}_{6} \mathrm{Cl}_{4}$ & - $\mathrm{BTC}$ \\
III & 0.57 & - & $78 \sim 78.5$ & 254 & $\mathrm{C}_{6} \mathrm{H}_{7} \mathrm{Cl}_{5}$ & eaaae-Cl \\
IV & 0.88 & - & $74 \sim 75$ & 254 & $\mathrm{C}_{8} \mathrm{H}_{7} \mathrm{Cl}_{5}$ & eaeee-Cl \\
\hline
\end{tabular}

a Relative to the value of $\gamma-\mathrm{BHC}$. See the text for experimental details.

of $m p$ and $I^{17)}$ and $\mathrm{NMR}^{18,15)}$ spectra, and the retention times on GLC with those of authentic sample, compound $\mathbf{I}$ corresponds to $\gamma$-isomer of tetrachlorocyclohexene. Thus, its steric configuration is $3 \alpha, 4 \alpha, 5 \beta, 6 \alpha$ or the conformation of the chlorine atoms is $3 \mathrm{a} 4 \mathrm{e} 5 \mathrm{e} 6 \mathrm{e}$ as shown in I of Fig. 4.

The second compound (II) whose relative retention time on $\mathrm{OV}-17$ column was 0.33 and that on OV-210 column was 0.24 , showed $\mathrm{mp}$ $99 \sim 100^{\circ} \mathrm{C}$ and $\mathrm{M}^{+} 218$. This compound is also an isomer of tetrachlorocyclohexene $\left(\mathrm{C}_{6} \mathrm{H}_{6} \mathrm{Cl}_{4}\right)$ from elementary analysis and $\mathrm{MS}$ spectrum. The IR spectrum, $\mathrm{mp}$, the retention times on GLC and coupling constants of the NMR spectrum ${ }^{19}$ are consistent with those of $\varepsilon$-isomer of tetrachlorocyclohexene. Therefore, the steric configuration of II, viz., the $\varepsilon$-isomer is $3 \alpha, 4 \alpha, 5 \alpha, 6 \beta$ or the conformation of the chlorine atoms is $3 \mathrm{e} 4 \mathrm{a} 5 \mathrm{e} 6 \mathrm{e}$ as shown in II of Fig. 4.

The third compound (III) whose relative retention time on $\mathrm{OV}-17$ column was 0.57 , showed $\mathrm{mp} 78 \sim 78.5^{\circ} \mathrm{C}$ and $\mathrm{M}^{+} 254$. This compound is an isomer of pentachlorocyclohexane $\left(\mathrm{C}_{6} \mathrm{H}_{7} \mathrm{Cl}_{5}\right)$ from elementary analysis and MS spectrum. From mp and NMR spectrum, and the retention time on GLC, compound III corresponds to the known meso-pentachloro-
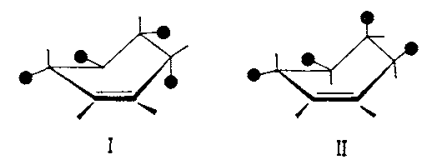

FIG. 4. Conformations of Compounds I (3a,4e,5e,6e$\mathrm{Cl})$ and $\mathrm{II}(3 \mathrm{e}, 4 \mathrm{a}, 5 \mathrm{e}, 6 \mathrm{e}-\mathrm{Cl})$. cyclohexane in which the conformation of the chlorine atoms was concluded to be 1 e $2 \mathrm{a} 3 \mathrm{a}$ $4 \mathrm{a}$ 5e from both of the NMR spectrum and the calculation of the free energy difference between two conformational isomers. ${ }^{15)}$

The X-ray crystal structure analysis of this compound showed that the crystals are formed in a monoclinic, space group $P 2_{1} / c, a=7.677(1)$, $b=12.126(1), c=20.970(1) \AA, \beta=91.85(1)^{\circ}$, and $z=8$. The structure was solved by direct method and refined by a block diagonal least square method. From the perspective view shown in Fig. 5, we confirmed that the configuration of this isomer is $1 \alpha, 2 \alpha, 3 \beta, 4 \alpha, 5 \alpha$ and the conformation of chlorine atoms is 1e $2 \mathrm{a} 3 \mathrm{a} 4 \mathrm{a} 5 \mathrm{e}$. This result is consistent with the conclusion reached by Tanaka et al. ${ }^{15)}$

The forth compound (IV) whose relative retention time on $\mathrm{OV}-17$ column was 0.88 , showed $\mathrm{mp} 75^{\circ} \mathrm{C}$ and $\mathrm{M}^{+} 254$. From the NMR and MS spectra shown in Fig. 6 and elementary analysis, this compound is an isomer of pentachlorocyclohexane. While two steric isomers of $1,2,3,4,5$-pentachlorocyclo-

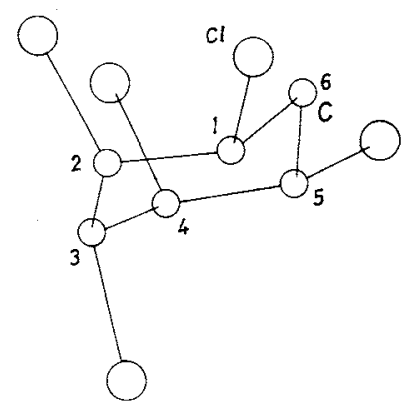

FIG. 5. A Perspective View of Compound III $(1 \mathrm{e}, 2 \mathrm{a}, 3 \mathrm{a}, 4 \mathrm{a}, 5 \mathrm{e}-\mathrm{Cl})$. 


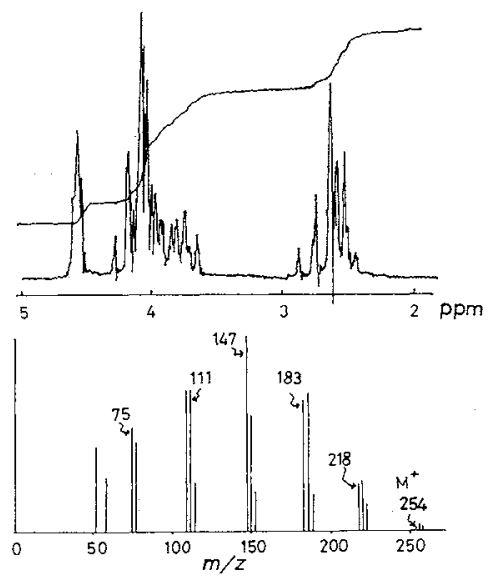

FIG. 6. NMR and Mass Spectra of Compound IV $(1 \mathrm{e}, 2 \mathrm{a}, 3 \mathrm{e}, 4 \mathrm{e}, 5 \mathrm{e}-\mathrm{Cl})$.

hexane were so far obtained and their configurations were determined, one of them is the known racemic isomer obtained by the irradiation of a crystalline state of $\gamma-\mathrm{BHC}$ and the other is the meso-isomer corresponding to the compound III. The compound IV is a new conformational isomer of pentachlorocyclohexane which corresponds to neither of them.

Since the elucidation of the steric configuration of this compound by chemical and spectral investigation was difficult, X-ray crystal structure analysis was undertaken. ${ }^{16,20)}$ Crystals were formed in the monoclinic, space group $P 2_{1} / c, a=8.061(1), \quad b=7.992(1), \quad c=$ 16.554(3) $\AA, \quad \beta=110.43(1)^{\circ}, \quad z=4, \quad D_{\mathrm{x}}=1.70$, $D_{\mathrm{m}}=1.68 \mathrm{~g} / \mathrm{cm}^{3}$. The structure was solved by the direct method and refined by a block diagonal least square method. The perspective view shown in Fig. 7 indicates $1 \alpha, 2 \alpha, 3 \alpha$, $4 \beta, 5 \alpha$ configuration or 1 e 2 a 3 e 4 e 5 e conformation of the chlorine atoms, although the cyclohexane ring is a little distorted.

With ragard to the conformation of tetrachlorocyclohexenes and pentachlorocyclohexanes produced by the irradiation of $\gamma$ isomer of BHC in 2-propanol, we anticipated the formation of $\alpha$-isomer of tetrachlorocyclohexene $\left(3 \mathrm{a}, 4 \mathrm{a}, 5 \mathrm{e}, 6 \mathrm{e}-\mathrm{C}_{6} \mathrm{H}_{6} \mathrm{Cl}_{4}\right)$ and the known racemic isomer of pentachlorocyclohexane (1a, $2 \mathrm{a}, 3 \mathrm{e}, 4 \mathrm{e}, 5 \mathrm{e}-\mathrm{C}_{6} \mathrm{H}_{7} \mathrm{Cl}_{5}$ ) through intermediary

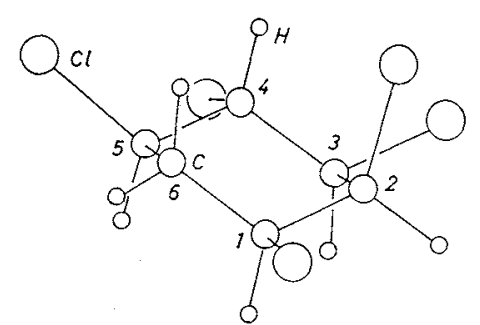

FIG. 7. A Perspective view of Compound IV (1e,2a, 3e,4e, 5e-Cl).

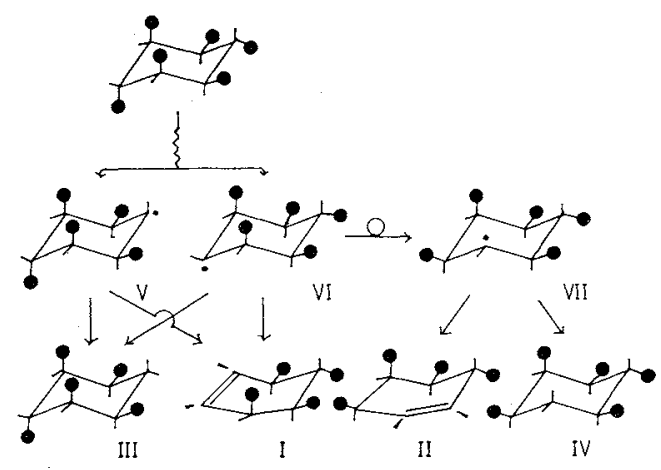

FIG. 8. Proposed Pathway to Tetrachlorocyclohexenes $\left(\mathrm{C}_{6} \mathrm{H}_{8} \mathrm{Cl}_{4}\right)$ and Pentachlorocyclohexanes $\left(\mathrm{C}_{6} \mathrm{H}_{7} \mathrm{Cl}_{5}\right)$ in the Radiolysis of $\gamma$-Isomer of $\mathrm{BHC}$ in 2-Propanol.

Symbol $\stackrel{0}{\rightarrow}$ means the reaction involving the migration of a $\mathrm{Cl}$ atom from a to e position.

1a,2a,3e,4e,5e-pentachlorocyclohexyl radical produced by the irradiation. Eventually, we could not identify the production of either compound, but confirmed the formation of both $\gamma_{-}(3 \mathrm{a}, 4 \mathrm{e}, 5 \mathrm{e}, 6 \mathrm{e}-\mathrm{Cl})$ and $\varepsilon$-isomer $(3 \mathrm{e}, 4 \mathrm{a}$, $5 \mathrm{e}, 6 \mathrm{e}-\mathrm{Cl})$ of tetrachlorocyclohexene and both $1 \mathrm{e}, 2 \mathrm{a}, 3 \mathrm{a}, 4 \mathrm{a}, 5 \mathrm{e}-\mathrm{Cl}$ and $1 \mathrm{e}, 2 \mathrm{a}, 3 \mathrm{e}, 4 \mathrm{e}, 5 \mathrm{e}-\mathrm{Cl}$ isomer of pentachlorocyclohexane.

Based on the above findings, we propose the following stereochemical scheme to the radiolysis or photolysis of $\gamma$-isomer of $\mathrm{BHC}$ in 2-propanol. As shown in Fig. 8, 1e,2a,3a, $4 \mathrm{a}, 5 \mathrm{e}-(\mathbf{V})$ and $1 \mathrm{a}, 2 \mathrm{e}, 3 \mathrm{e}, 4 \mathrm{e}, 5 \mathrm{a}-$ pentachlorocyclohexyl (VI) radicals may be formed as the intermediates, while neither $1 \mathrm{a}, 2 \mathrm{a}, 3 \mathrm{e}, 4 \mathrm{e}, 5 \mathrm{e}-*$

* The compound I might be formed from this radical (1a, $2 \mathrm{a}, 3 \mathrm{e}, 4 \mathrm{e}, 5 \mathrm{e}$ ), but the absence of the $1 \mathrm{a}, 2 \mathrm{a}, 3 \mathrm{e}, 4 \mathrm{e}, 5 \mathrm{e}$ isomer of pentachlorocyclohexane in the products seems to exclude the possible intervention of this radical. 
nor $1 \mathrm{a}, 2 \mathrm{a}, 3 \mathrm{a}, 4 \mathrm{e}, 5 \mathrm{e}$-pentachlorocyclohexyl radicals seems to be produced. Both 1e,2a,3a, 4a,5e-pentachlorocyclohexane (III) and $\gamma$ tetrachlorocyclohexene (I) may be obtained from the radicals $\mathbf{V}$ and $\mathrm{VI}$; on the occasion, III may be formed by the abstraction of hydrogen from the surroundings and I by the dechlorination. 1e,2a,3e,4e,5e-Pentachlorocyclohexane (IV) and $\varepsilon$-tetrachlorocyclohexene (II) are considered to be obtained only through the isomerization of intermediary radicals. The migration of a chlorine or bromine atom to the neighboring position during a free radical chain reaction was demonstrated in the radiation-induced reaction of simple halogenated alkanes. ${ }^{21 \sim 23)}$ Therefore, one of the two axial chlorine atoms existing in meta positions to each other in 1a,2e,3e,4e,5a-pentachlorocyclohexyl radicals (VI) may be transferred to neighboring equatorial position to produce 1e,2a,3e,4e,5e-pentachlorocyclohexyl radicals (VII). From the new radicals formed, both 1e,2a,3e,4e,5e-pentachlorocyclohexane

(IV) and $\varepsilon$-tetrachlorocyclohexene (II) may be obtained by the abstraction of hydrogen and the dechlorination, respectively.

In the reaction of $\gamma$-BHC in 2-propanol, hydrochloric acid and acetone were produced besides chlorinated hydrocarbons. $G$-values of the formation of identified products and the consumption of $\gamma$-BHC for $60 \mathrm{~min}$ irradiation at three dose rates are shown in Table II. The data in the Table fluctuate considerably since various unidentified minor compounds
TABle II. Product Yieldo ( $G$ Values) in the RADIOLYSIS OF $\gamma$-ISOMER OF BHC IN 2-PROPANOL

\begin{tabular}{lrrr}
\hline $\begin{array}{l}\text { Dose rate } \\
\times 10^{17} \mathrm{eV} / \mathrm{g}, \mathrm{min}\end{array}$ & 4.83 & 2.42 & 1.21 \\
\hline Compd. I & 5.2 & 7.5 & 8.7 \\
Compd. II & 3.4 & 4.8 & 5.5 \\
Compd. III & 5.4 & 7.6 & 8.9 \\
Compd. IV & 7.4 & 10.3 & 13.6 \\
HCl & 87.5 & 122.7 & 158.9 \\
Acetone & 48.7 & 70.0 & 93.4 \\
$-(\gamma-B H C)^{a}$ & 42.0 & 51.2 & 64.0 \\
\hline
\end{tabular}

a Consumption of $\gamma-\mathrm{BHC}$.

are produced in the reaction. In each dose rate, the $G$-value of $\gamma$-BHC consumption is appreciably higher than the overall $G$-value of the four identified products because of the above reason, $G$-value of $\mathrm{HCl}$ is a little higher than 1.5 times that of acetone, and that of acetone is fairly higher than that of $\gamma$-BHC consumption. Since the free radical chain mechanism postulated for the irradiation of chlorinated hydrocarbon in 2-propanol ${ }^{9}$ seems to be applicable to $\gamma$-BHC radiolysis in 2 propanol, and since both tetrachlorocyclohexenes and pentachlorocyclohexanes were obtained simultaneously in the nearly same amount, the following schemes of radical chain mechanism are presented for the irradiation reaction in spite of some discrepancies among the yields of products.

\section{EXPERIMENTAL}

Material. The $\alpha-, \beta-, \gamma$ - and $\delta$-isomers of $\mathrm{BHC}$ purchased from Tokyo Kasei Co., were recrystallized

$$
\begin{aligned}
& \left(\mathrm{CH}_{3}\right)_{2} \mathrm{CHOH} \cdot m \longrightarrow x \text { (free radical or solvated electron) } \\
& \mathrm{X}+\mathrm{C}_{6} \mathrm{H}_{6} \mathrm{Cl}_{6} \longrightarrow \mathrm{xCl}+\mathrm{C}_{6} \mathrm{H}_{6} \mathrm{Cl}_{5} \text {. } \\
& \text { a) } \mathrm{C}_{6} \mathrm{H}_{6} \mathrm{Cl}_{5}+\left(\mathrm{CH}_{3}\right)_{2} \mathrm{CHOH} \longrightarrow \mathrm{C}_{6} \mathrm{H}_{7} \mathrm{Cl}_{5}+\left(\mathrm{CH}_{3}\right)_{2} \dot{\mathrm{COH}} \\
& \left(\mathrm{CH}_{3}\right)_{2} \dot{\mathrm{COH}}+\mathrm{C}_{6} \mathrm{H}_{5} \mathrm{Cl}_{6} \longrightarrow \underline{\left(\mathrm{CH}_{3}\right)_{2} \mathrm{CO}}+\underline{\mathrm{HCl}}+\mathrm{C}_{6} \mathrm{H}_{6} \mathrm{Cl}_{5} \text {. } \\
& \text { b) } \mathrm{C}_{6} \mathrm{H}_{6} \mathrm{Cl}_{5}+\longrightarrow \mathrm{C}_{6} \mathrm{H}_{6} \mathrm{Cl}_{4}+\mathrm{Cl} \text {. } \\
& \mathrm{Cl} \cdot+\left(\mathrm{CH}_{3}\right)_{2} \mathrm{CHOH} \longrightarrow\left\langle\mathrm{CH}_{3}\right)_{2} \dot{\mathrm{COH}}+\underline{\mathrm{HCl}}
\end{aligned}
$$

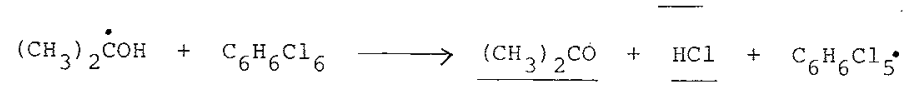


from 2-propanol prior to use. $\varepsilon$-Isomer of $\mathrm{BHC}$ was supplied from Dow Chem., U.S.A. Other reagents were used as received.

Gamma-irradiation. The irradiation was carried out in the irradiation room of our Institute where the samples were placed radially around a ${ }^{60} \mathrm{Co}$ source (approximately $6000 \mathrm{Ci}$ ). Pulverized crystals of $\alpha$-, $\beta-, \gamma$-and $\delta$-isomer of BHC in Pyrex tube were irradiated by ${ }^{60} \mathrm{Co} \gamma$-ray for $200 \mathrm{hr}$ at a dose rate $5 \times 10^{5} \mathrm{R} / \mathrm{h}$.

Each solution $(\alpha-, \gamma-, \delta$ - and $\varepsilon$-isomer, $1.5 \mathrm{w} / \mathrm{v} \%$; $\beta$-isomer, $0.23 \mathrm{w} / \mathrm{v} \%$ ) of $\mathrm{BHC}$ isomer dissolved in 2propanol was placed in Pyrex tube, deaerated by flushing with argon, sealed with a rubber cap and irradiated with ${ }^{60} \mathrm{Co} \gamma$-ray. Dose rates were varied from $1.25 \times 10^{5}$ to $5 \times 10^{5} \mathrm{R} / \mathrm{h}$. After certain time of irradiation, an aliquot of each sample was taken out by a syringe for GLC analysis.

UV-irradiation. The solution $(1.5 \mathrm{w} / \mathrm{v} \%)$ of $\gamma$ isomer of BHC in 2-propanol was irradiated by UV light of $15 \mathrm{~W}$ low pressure mercury lamp (Taiko Co., Kyoto) immersed in the reaction vessel.

Gas-chromatography (GLC). Gas-chromatographic analysis was performed on a Shimadzu 6A gas-chromatograph equipped with ECD. The column used was a glass tube of $200 \mathrm{~cm}$ long and $3 \mathrm{~mm}$ inside diameter packed with $3 \% \mathrm{OV}-17$ on Chromosorb GAW, DMCS. Flow rate of nitrogen was $50 \mathrm{~m} 1 / \mathrm{min}$.

Gas-chromatography and Mass spectrometry (GC/MS). Shimadzu-LKB-9000 was used for GC/MS analysis. The gas-chromatographic portion was equipped with column of $200 \mathrm{~cm}$ long (inside diameter $3 \mathrm{~mm}$ ) packed with $0.5 \%$ OV-17 on Chromosorb GAW DMCS operated $170^{\circ} \mathrm{C}, 100 \mathrm{~cm}$ long packed with $3 \%$ OV-17 on Chromosorb GAW DMCS operated at $160^{\circ} \mathrm{C}$ or $300 \mathrm{~cm}$ long packed with $5 \%$ OV-210 on Chromosorb GAW DMCS operated at $120^{\circ} \mathrm{C}$. Flow rate of helium was $30 \mathrm{ml} / \mathrm{min}$.

In mass spectroscopic analysis, the temperatures of the separator and the ion source were $200^{\circ} \mathrm{C}$ and $290^{\circ} \mathrm{C}$. Ionization potential was $70 \mathrm{eV}$.

Preparative liquid chromatography. A $60 \mathrm{~cm} \times$ $1.2 \mathrm{~cm}$ glass column packed with $27 \mathrm{~g}$ of silicic acid (Mallinckrodt Co.) moistened with $11 \mathrm{~g}$ of nitromethane was used. Solvent for elution was hexane saturated with nitromethane. Each $2 \sim 3 \mathrm{~g}$ of the eluted solution was collected by a fraction collector.

High performance liquid chromatography. HPLC analysis was performed on Waters Associates apparatus. The column was $\mu$-Porasil $(\mathbb{B})$ of $250 \mathrm{~mm}$ long and $4.6 \mathrm{~mm}$ diameter. The solvent was $\mathrm{CHCl}_{3} /$ iso-octane $=1: 18$ and the flow rate was $2 \mathrm{ml} / \mathrm{min}$.
$X$-ray crystal structure analysis. ${ }^{20)}$ Three dimensional intensity data were collected on a Hilger and Watts Y-290 diffractometer with Zr-filtered Mo $\mathrm{K} \alpha$ radiation. The structure was solved by use of the program MULTAN with local modification on a FACOM 270-30 computer, and refined by a block diagonal least square method.

NMR spectroscopy. NMR spectra were recorded on a JEOL MH-100, using $\mathrm{CCl}_{4}$ or $\mathrm{CDCl}_{3}$ as solvents and TMS as internal standard.

IR spectroscopy. IR spectra were recorded by $\mathrm{KBr}$ disk on a JASCO IR-S.

Products analysis. Analyses of parent and degradation products were performed by GLC using $3 \%$ OV-17 and 5\% OV-210 column. Hydrogen chloride produced was measured by acid-base titration. Acetone was analysed on GLC using $15 \%$ DEGS column.

Purification of irradiated products of crystalline $\gamma-B H C$. The most abundant compound isolated from the irradiated product by the repeated liquid chromatography was $\alpha$-isomer of $\mathrm{BHC}$ which was identified by $\mathrm{mp}$, IR and the retention time of OV-17 column of GLC. By repeated chromatography and recrystallization of the fraction containing the second major product, a compound of $\mathrm{mp} 104 \sim 106^{\circ} \mathrm{C}$ was isolated. $\mathrm{M}^{+}$of $\mathrm{C}_{6} \mathrm{H}_{7}{ }^{85} \mathrm{Cl}_{5}$ was 254. Anal. Found: C, 27.32; $\mathrm{H}, 2.51$. Calcd. for $\mathrm{C}_{8} \mathrm{H}_{7} \mathrm{Cl}_{5}: \mathrm{C}, 28.11 ; \mathrm{H}, 2.75$. This compound was an isomer of pentachlorocyclohexane. The retention time on GLC and the IR and NMR spectra agreed with those of racemic-1a,2a,3e,4e,5epentachlorocyclohexane prepared by the chlorinarion of $1 \mathrm{a}, 2 \mathrm{a}, 4 \mathrm{e}, 5 \mathrm{e}$-tetrachlorocyclohexene. ${ }^{14}$ The third major compound isolated by repeated chromatography corresponded to $\delta$-isomer of $\mathrm{BHC}$ by $\mathrm{mp}$ and the retention time on OV-17 column of GLC.

Isolation of four compounds from the irradiated product of $\gamma$-BHC in 2-propanol. Compound I $(3 \mathrm{a}, 4 \mathrm{e}, 5 \mathrm{e}, 6 \mathrm{e}-$ tetrachlorocyclohexene, $\gamma$-BTC): Preparative liquid chromatography and recrystallization of the irradiated product afforded compound I of $\mathrm{mp} 86 \sim 87^{\circ} \mathrm{C} . \mathrm{M}^{+}$ for $\mathrm{C}_{8} \mathrm{H}_{6}{ }^{35} \mathrm{Cl}_{4}$ was 218. Anal. Found: C, 32.99; $\mathrm{H}$, 2.79. Calcd. for $\mathrm{C}_{8} \mathrm{H}_{8} \mathrm{Cl}_{4}: \mathrm{C}, 32.73 ; \mathrm{H}, 2.72$. The $I^{17)}$ and $\mathrm{NMR}^{18)}$ spectra and the retention times on GLC and HPLC agreed with those of $\gamma$-isomer of 3,4,5,6-tetrachlorocyclohexene (BTC) (mp 88.2 $88.8^{\circ} \mathrm{C}^{177)}$.

Compound II (3e,4a,5e,6e-tetrachlorocyclohexene, $\varepsilon$ BTC): After repeated liquid chromatography and recrystallization of compound II-rich fractions of the irradiated product, compound II of $\mathrm{mp} 99 \sim 100^{\circ} \mathrm{C}$ was obtained. $\mathrm{M}^{+}$for $\mathrm{C}_{6} \mathrm{H}_{6}{ }^{35} \mathrm{Cl}_{4}$ was 218 . Anal. Found: C, 32.51; H, 2.69. Calcd. for $\mathrm{C}_{6} \mathrm{H}_{6} \mathrm{Cl}_{4}: \mathrm{C}, 32.73$; 
$H, 2.72$. The IR spectrum and the retention times on GLC and HPLC and the coupling constants of the $\mathrm{NMR}^{19)}$ agreed with those of $\varepsilon$-isomer of tetrachlorocyclohexene (BTC) (mp 98.7 99.3 $3^{\circ} \mathrm{C}^{15,17)}$ ).

CompoundIII(meso-1e,2a,3a,4a,5e-pentachlorocyclohexane): After repeated liquid chromatography and recrystallization of the irradiated product, compound III of $\mathrm{mp} 78 \sim 78.5^{\circ} \mathrm{C}$ was obtained. $\mathrm{M}^{+}$for $\mathrm{C}_{6} \mathrm{H}_{7}{ }^{25} \mathrm{Cl}_{5}$ was 254. Anal. Found: C, 28.19; H, 2.66. Caled. for $\mathrm{C}_{6} \mathrm{H}_{7} \mathrm{Cl}_{5}: \mathrm{C}, 28.11 ; \mathrm{H}, 2.75$. The NMR spectrum and the retention time on GLC agreed with those of mesopentachlorocyclohexane ( $\left.\mathrm{mp} 78^{\circ} \mathrm{C}^{15}\right)$ ). MS: $\mathrm{m} / z: 254$ $\left(5, \mathrm{M}^{+}\right), 218(15,-\mathrm{HCl}), 183(100,-(\mathrm{HCl}+\mathrm{Cl})), 147$ $(96,-(\mathrm{Cl}+2 \mathrm{HCl})), 111(75,-(\mathrm{Cl}+3 \mathrm{HCl}))$.

Compound IV (1e,2a,3e,4e,5e-pentachlorocyclohexane): By liquid chromatography and recrystallization of the irradiated product, compound IV of mp $74 \sim 75^{\circ} \mathrm{C}$ was isolated. $\mathrm{M}^{+}$for $\mathrm{C}_{6} \mathrm{H}_{7}{ }^{35} \mathrm{Cl}_{5}$ was 254. Anal. Found: C, $28.27 ; \mathrm{H}, 2.63$. Calcd. for $\mathrm{C}_{6} \mathrm{H}_{7} \mathrm{Cl}_{5}:\left[\mathrm{C}, 28.11 ; \mathrm{H}, 2.75\right.$. NMR: $\delta_{\mathrm{Me}}^{\mathrm{CDCl} i}: 4.56$ (approx. triplet $\mathrm{CHCl}$ ) 4.1 (multiplet; $\mathrm{CHCl}$ ) and 2.6 (multiplet; $\mathrm{CH}_{2}$ (H-6a and $\left.\mathrm{H}-6 \mathrm{e}\right)$ ) $\mathrm{MS}: m / z: 254$ $\left(1, \mathrm{M}^{+}\right), 218(23,-\mathrm{HCl}), 183(77,-(\mathrm{Cl}+\mathrm{HCl})), 147$ $(100,-(\mathrm{Cl}+2 \mathrm{HCl})), 111(79,-(\mathrm{Cl}+3 \mathrm{HCl}))$.

Acknowledgment. The authors wish to express their grateful appreciation to Dr. N. Kurihara of Radioisotope Research Center, Kyoto University for providing meso-pentachlorocyclohexane and for helpful suggestions.

\section{REFERENCES}

1) L. O. Ruzo, M. J. Zabik and R. D. Schuetz, J. Agr. Food Chem., 22, 199 (1974).

2) L. O. Ruzo, M. J. Zabik and R. D. Schuetz, J. Am. Chem. Soc., 96, 3809 (1974).

3) N. J. Bunce, Y. Kumar, L. Revanal and S. Safe, J. Chem. Soc., Perkin II, 1978, 880.

4) T. Sawai and Y.Shinozaki, Chem. Lett., 1972, 865.

5) T. Sawai, T. Shimokawa and Y. Shinozaki, Bull.
Chem. Soc. Jpn, 47, 1889 (1974).

6) T. Nishiwaki, M. Usui, K. Anda and M. Hida, Bull. Chem. Soc. Jpn, 52, 821 (1979).

7) S. Arai, M. Matsui, J. Moriguchi and M. Imamura, Rep. Inst. Phys. Chem. Res., 48, 185 (1972).

8) W. V. Sherman, R. Evans, E. Nesyto and C. Radlowski, Nature, 232, 119 (1971).

9) R. Evans, E. Nesyto, C. Radlowski and W. V. Sherman, J. Phys. Chem., 75, 2762 (1971).

10) A. R. Mosier, W. D. Guenzi and L. L. Miller, Science, 164, 1083 (1969).

11) H. Elias and O. Christ, Int. J. Appl. Rad. Isotopes, 17, 293 (1966).

12) Y. Ogata, K. Takagi and Y. Sasoh, Bull. Chem. Soc. Jpn., 52, 884 (1979).

13) Y. Matsui, M. Eto and K. Maekawa, Nippon Nôgeikagaku Kaishi, 47, 599 (1973).

14) R. Jaunin and A. Germano, Helv. Chim. Acta, 38, 1763 (1955).

15) K. Tanaka, M. Kiso, M. Yoshida, N. Kurihara and M. Nakajima, Agric. Biol. Chem., 39, 229 (1975).

16) M. Hamada, E. Kawano, S. Kawamura and M. Shiro, Tetrahedron Lett., 1977, 2409.

17) H.D. Orloff, A. J. Kolka, G. Calingaert, M. E. Griffing and E. R. Kerr, J. Am. Chem. Soc., 75, 4243 (1953).

18) N. Kurihara, Y. Sanemitsu, M. Nakajima, G. E. McCasland and L. F. Johnson, Agric. Biol. Chem., 35, 71 (1971).

19) Y.Sanemitsu, N. Kurihara, M. Nakajima, G. E. McCasland, L. F. Johnson and L. C. Carey, Agric. Biol. Chem., 36, 845 (1972).

20) M. Shiro, H. Nakai and M. Hamada, Acta Cryst., B34, 3812 (1978).

21) H. L. Benson and J. E. Willard, J. Am. Chem. Soc., 88, 5689 (1966).

22) M. Takehisa, G. Levey and J. E. Willard, J. Am. Chem. Soc., 88, 5694 (1966).

23) D. H. Martin and F. Williams, J. Am. Chem. Soc., 92, 769 (1970). 